\title{
Mark-Recapture and Stochastic Population Models for Polar Bears of the High Arctic
}

\author{
MITCHELL K. TAYLOR, ${ }^{1}$ JEFF LAAKE, ${ }^{2}$ PHILIP D. McLOUGHLIN,${ }^{3,4}$ H. DEAN CLUFF ${ }^{5}$ and FRANÇOIS MESSIER ${ }^{3}$
}

(Received 20 April 2007; accepted in revised form 23 October 2007)

\begin{abstract}
We used mark-recapture data and population viability analysis (PVA) to estimate demographic parameters, abundance, and harvest risks for two adjacent populations of polar bears (Ursus maritimus) inhabiting Lancaster Sound and Norwegian Bay, Canada. Analyses were based on data from 1871 bears that were uniquely marked during the period 1972-97. Our best-fitting mark-recapture model specified sex and age effects on probabilities of survival and an effect of prior recapture (dependence) on capture probability. The most parsimonious solution in our analysis of survival was to assume the same rate for the Lancaster Sound and Norwegian Bay populations. Total (harvested) annual survival rates (mean $\pm 1 \mathrm{SE}$ ) for females included: $0.749 \pm 0.105$ (cubs), $0.879 \pm 0.050$ (ages 1-4), $0.936 \pm 0.019$ (ages 5-20), and $0.758 \pm 0.054$ (ages 21+). Mean litter size was $1.69 \pm 0.01$ cubs for females of Lancaster Sound and $1.71 \pm 0.08$ cubs for females of Norwegian Bay. By age six, on average 0.31 \pm 0.21 females of Lancaster Sound were producing litters (first age of reproduction was five years); however, females of Norwegian Bay did not reproduce until age seven or more. Total abundance (1995-97) averaged $2541 \pm 391$ bears in Lancaster Sound and $203 \pm 44$ bears in Norwegian Bay. The finite rate of increase $(\lambda)$ during the study period was estimated to be $1.001 \pm$ 0.013 for bears of Lancaster Sound and $0.981 \pm 0.027$ for bears of Norwegian Bay. We incorporated demographic parameters into a harvest-explicit PVA to model short-term (15 yr) probabilities of overharvesting (i.e., 1997-2012). Our harvest simulations suggest that current levels of kill are approaching and perhaps exceeding the sustainable yield in both populations.
\end{abstract}

Key words: demography, harvest, mark-recapture, polar bear, population viability analysis (PVA), program MARK, Ursus maritimus

RÉSUMÉ. Nous avons recouru aux données obtenues par marquage et recapture ainsi qu'aux analyses de viabilité de population pour estimer les paramètres démographiques, l'abondance et les risques liés à la récolte de deux populations adjacentes d'ours polaires (Ursus maritimus) évoluant dans le détroit de Lancaster et la baie Norwegian, au Canada. Les analyses reposaient sur les données relatives à 1871 ours marqués de manière unique pendant la période allant de 1972 à 1997 . Notre modèle de marquage et recapture le mieux ajusté tenait compte des effets du sexe et de l'âge sur les probabilités de survie, ainsi que de l'effet d'une recapture antérieure (dépendance) sur la probabilité de capture. La solution la plus parcimonieuse de notre analyse de survie consistait à assumer le même taux pour les populations du détroit de Lancaster et de la baie Norwegian. Les taux totaux de survie annuels (récoltés) (moyenne $\pm 1 \mathrm{SE}$ ) chez les femelles s'établissaient comme suit : 0,749 $\pm 0,105$ (oursons), 0,879 $\pm 0,050$ (âges 1-4), 0,936 $\pm 0,019$ (âges 5-20), et 0,758 $\pm 0,054$ (âges 21+). La grosseur moyenne des portées était de 1,69 $\pm 0,01$ ourson dans le cas des femelles du détroit de Lancaster, et de 1,71 $\pm 0,08$ ourson dans le cas des femelles de la baie Norwegian. Avant l'âge de six ans, en moyenne 0,31 $\pm 0,21$ femelle du détroit de Lancaster produisait des portées (l'âge de reproduction le plus jeune était de cinq ans); cependant, les femelles de la baie Norwegian ne se reproduisaient pas avant l'âge de sept ans ou plus. L'abondance totale (1995-1997) atteignait en moyenne $2541 \pm 391$ ours au détroit de Lancaster, et $203 \pm 44$ ours dans la baie Norwegian. Le taux fini d'augmentation $(\lambda)$ pendant la période d'étude était estimé à 1,001 $\pm 0,013$ dans le cas des ours du détroit de Lancaster, et de 0,981 $\pm 0,027$ dans le cas des ours de la baie Norwegian. Nous avons intégré les paramètres démographiques à une analyse de viabilité de population de récolte explicite pour modéliser les probabilités à court terme (15 ans) de surrécolte (i.e. 1997-2012). Nos simulations de récolte laissent croire que les taux d'ours tués approchent et peuvent même dépasser le rendement admissible des deux populations.

Mots clés : démographie, récolte, marquage et recapture, ours polaire, analyse de viabilité de population, programme MARK, Ursus maritimus

Traduit pour la revue Arctic par Nicole Giguère.

\footnotetext{
${ }^{1}$ Department of the Environment, Government of Nunavut, P.O. Box 209, Igloolik, Nunavut X0A 0L0, Canada

${ }^{2}$ National Marine Mammal Laboratory, Alaska Fisheries Science Center, National Marine Fisheries Service, Seattle, Washington 98115, USA

${ }^{3}$ Department of Biology, University of Saskatchewan, 112 Science Place, Saskatoon, Saskatchewan S7N 5E2, Canada

${ }^{4}$ Corresponding author: philip.mcloughlin@usask.ca

${ }^{5}$ Department of Environment and Natural Resources, North Slave Region, Government of the Northwest Territories, Yellowknife, Northwest Territories X1A 2P9, Canada

(C) The Arctic Institute of North America
} 


\section{INTRODUCTION}

Recently, the effects of directional climate change in the Arctic on polar bears (Ursus maritimus Phipps) have dominated debate surrounding trends in populations and the role of polar bear hunting as a cultural and economic activity of northern indigenous peoples (ACIA, 2004; Derocher et al., 2004; Aars et al., 2006). Climate change will ultimately determine the future abundance and distribution of the species; however, in the archipelago of Canada's High Arctic, negative effects of climate change have yet to be reported for polar bears. Here, bear hunting remains of major cultural and economic importance to many northern residents (Freeman and Wenzel, 2006). Over the short term (e.g., the next 10-15 years), it is highly likely that hunting, rather than climate change, will play the primary role in determining trends of polar bear populations. Although alert to the potential for climate change to underlie changes in vital rates of polar bears, managers must continue to focus their efforts on ensuring sustainability of the legislated hunt given known rates of survival and reproduction.

The level of harvest that is sustainable depends on several factors, including population size, vital rates (natural rates of birth and death), and the sex and age composition of the harvest. Unfortunately, because vital rates and population size are regularly estimated with error, deterministic estimates of sustainable yields are rarely of value for managing populations. An alternative approach would be to manage for harvests that provide a reasonable likelihood of population persistence for some time into the future. Models of probability of persistence, such as stochastic Population Viability Analysis or PVA (reviewed in White, 2000), are ideal for incorporating uncertainty of input parameters into harvest models. When information is uncertain (e.g., because of sampling error or environmental and demographic stochasticity), any harvest level poses some risk to a population. PVA has the flexibility to provide managers with harvest compositions that are sustainable with an associated probability, but also consequences should a harvest later be deemed too severe, e.g., a required length of moratorium to restore the population (Taylor et al., 2002, 2005). Further, where links can be made between natural demographic rates and directional climate change (e.g., Western Hudson Bay; Aars et al., 2006), harvested PVA models might offer an important framework for estimating sustainable kills that track longer term changes in carrying capacity.

Here we used mark-recapture data (1871 uniquely marked individuals) collected from 1972 to 1997 to estimate demographic characteristics of polar bears inhabiting Lancaster Sound and Norwegian Bay, Nunavut, in Canada's High Arctic (Fig. 1). We incorporated demographic parameters as input into harvest risk analyses designed to take process and sampling uncertainty into account when generating outcomes; this analysis amounted to a harvested PVA. We discuss our results in view of the

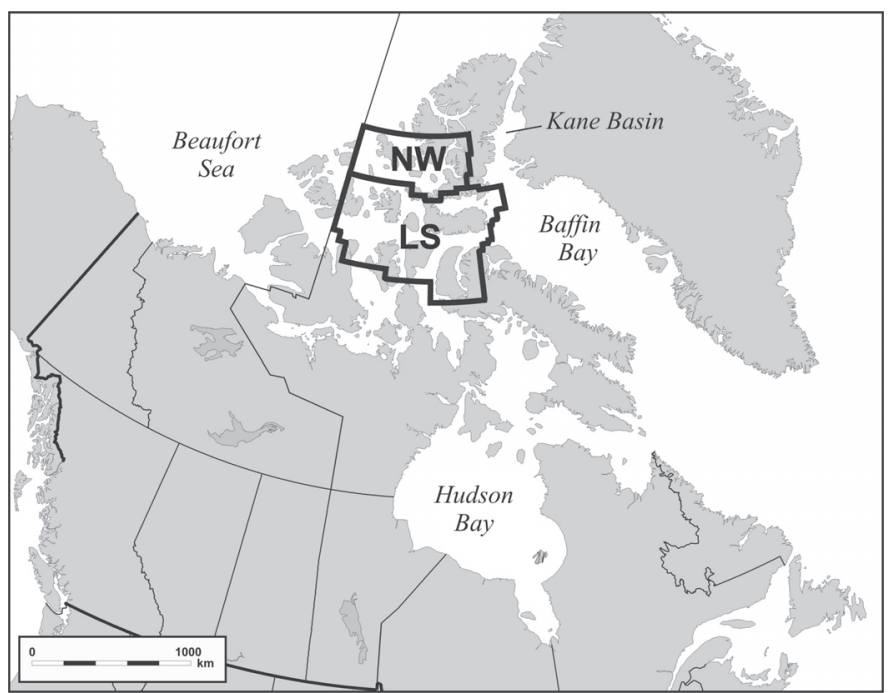

FIG. 1. Location of the Lancaster Sound (LS) and Norwegian Bay (NW) polar bear populations, Nunavut, Canada. Boundaries are defined as in Taylor et al. (2001).

short-term (15 yr) sustainability of the current hunt and present reasons why polar bears inhabiting the Far North of the Canadian Arctic Archipelago may be particularly at risk of overharvesting.

\section{METHODS}

\section{Study Area and Animals}

Polar bears in the study area were distributed primarily over the sea ice of Lancaster Sound and Norwegian Bay, Nunavut, Canada (Fig. 1). The geographic boundaries of the Lancaster Sound polar bear population and adjacent Norwegian Bay population had been established previously, using mark-recapture movement data (Taylor and Lee, 1995), DNA analysis (Paetkau et al., 1999), and cluster analysis of radio-telemetry data (Bethke et al., 1996; Taylor et al., 2001). The Norwegian Bay population was found to have a genetic structure distinct from that of the Lancaster Sound population (Paetkau et al., 1999), and this finding confirms the previous conclusion from movement data that little exchange of individuals occurs between the Norwegian Bay population and the Lancaster Sound or other identified polar bear populations (Taylor et al., 2001).

This study used data from two major capture programs in Lancaster Sound and Norwegian Bay: a general Arctic polar bear study conducted from 1972 to 1985 (Schweinsburg et al., 1981, 1982; Furnell and Schweinsburg, 1984) and a more recent inventory conducted from 1989 to 1997 (Lancaster Sound) and 1993 to 1997 (Norwegian Bay). From 1972 to 1992, captures were centralized around areas where bears were concentrated or communities that served as logistic bases, whereas from 1993 to 1997 captures were the result of a systematic, geographically uniform search of the entire study area. 
We chemically immobilized all bears and their dependent cubs for capture and marked bears according to procedures described by Stirling et al. (1989), following Animal Care Protocol No. 950005 of the University of Saskatchewan (under guidance of the Canadian Council on Animal Care). Bears captured from 1972 to 1985 were immobilized with phenylcyclidine hydrochloride (Furnell and Schweinsburg, 1984), but from 1989 to 1997, Telazol (tiletamine hydrochloride and zolazepam hydrochloride in combination) was used (Stirling et al., 1989). Upon its initial capture, each bear was assigned a unique identification number and marked accordingly with a plastic ear tag and a permanent lip tattoo. We also marked each bear on the fur with a wax crayon to ensure that bears were not captured more than once per year. Some animals were equipped with satellite radio collars to track their movements. We estimated the age of each handled bear by counting the annular rings of an extracted vestigial premolar (Calvert and Ramsay, 1998) unless the bear was captured as a cub of the year (i.e., cub) or yearling.

\section{Mark-Recapture Analysis}

Estimates of survival and abundance were constructed from capture-recapture data (1972 -97) using the CormackJolly-Seber (CJS) formulation implemented in program MARK (White and Burnham, 1999). The CJS likelihood for capture-recapture data is conditioned on initial capture events (i.e., the initial capture is treated as a release). The likelihood is based solely on recapture events of marked (i.e., previously caught) animals, and is defined by userspecified models for survival $(S)$ and (re)capture probabilities $(p)$ that may be expressed as functions of covariates such as sex, age, and time.

Captures of bears from 1972 to 1985 were used as initial captures, but we used only the recaptures from 1993 to 1997 because captures were geographically non-random and non-uniform before that time. To accommodate this structure, we ignored any recaptures from 1973 to 1992 and set the recapture probabilities to 0 in the model.

For the 1993-97 recapture data, we examined a series of models for capture probability that allowed for variation by time, population (Lancaster Sound or Norwegian Bay, both additive and interactive effects with other covariates), sex/age, radio collaring, and the result of prior capture events (trap dependence). We expected annual variation in capture probability because the number of flight hours and the capture teams varied by year. We also expected higher capture probabilities in Norwegian Bay because the smaller population size and smaller area to cover there made it more likely that we would have a relatively higher sample size (i.e., ratio of captures to total population size) than in Lancaster Sound. Bears with transmitters (radios) had a higher capture probability because their location was known at various times throughout the year. Only females were equipped with radios, but cubs and yearlings of a female with a transmitter were considered to have the same probability of capture as their mother.
Within the area searched in a given day, bears were located by visual observation and tracking from a helicopter. Successful location and eventual capture were likely to be affected by the number of bears in a group, their reaction to the helicopter, movement patterns, and fidelity to known areas of high use. To address these sources of heterogeneity, we considered models with age/sex effects and dependence on prior capture history. During spring, adult males and females with cubs and yearlings are typically in family groups, while subadults (age 2-4 years) are solitary. We considered models with different capture probabilities for these age groups (age). In another model, we expanded this classification with an adult male group (age/sex) and defined a time-varying covariate (family) with a value of 1 for yearlings and for adult female bears seen in the prior year in a family group and 0 otherwise. To address general heterogeneity in capture probability, we also considered a trap dependence model with a time-varying covariate (dependence) that had a value of 1 if the bear was seen in the prior year and 0 otherwise. The "dependence" covariate encompasses the "family" covariate. Because we only modeled recapture probability (condition on first capture) and never recaptured cubs (except as yearlings), we had to assume that they had the same capture probability as adult females.

For survival probability (apparent survival, which assumes no emigration during the study period), we considered models that included sex, age, and population. Survival was likely to vary by age, and we expected cubs and senescent adults to have lower survival. We considered an age-specific model that included different survival for cubs, subadults (aged 1-4 years), prime adults (5-20 years), and older adults (21+ years). We expected a sex effect in survival because more males were harvested than females. Since cubs are rarely harvested, we also considered a model that limited the sex effect to non-cubs. We did not consider annual differences in survival because we could not fit separate survival parameters for years before 1993, having excluded those recapture events. We also considered models with a population effect on survival (i.e., Lancaster Sound or Norwegian Bay).

We fitted a series of CJS models using each capture probability model with each survival probability model (White and Burnham, 1999). We considered additive models with main effects (e.g., sex + year) and a limited number of interactions (e.g., sex $\times$ age); however, there were too few data to support higher-order models. We used Akaike's Information Criterion adjusted for sample size and over-dispersion $\left(\mathrm{QAIC}_{c}\right)$ as a guide for model selection (Burnham and Anderson, 2002). The data were likely to be over-dispersed (i.e., greater than binomial variation) because survival and capture events of family groups (e.g., females with cubs or yearlings) were not independent. We estimated the over-dispersion coefficient, $\hat{c}$, from the number of dependent cub captures $\left(N_{c}\right)$ relative to all captures, $N$ (i.e., $N /\left(N-N_{c}\right)$; see Appendix in Taylor et al., 2002). We also compared this estimate to an estimate of $\hat{c}$ 
computed from the RELEASE goodness-of-fit tests, as suggested by Lebreton et al. (1992). We ranked the model with the lowest $\mathrm{QAIC}_{c}$ as best, and we used differences in $\mathrm{QAIC}_{c}$ between the best-fitting model and every other model $\left(\Delta \mathrm{QAIC}_{c}\right)$ to identify other likely models. We followed Burnham and Anderson (2002) in selecting likely models and produced model-averaged estimates from models with strong or some support $(\triangle \mathrm{QAIC} c<4.5)$.

We constructed abundance estimates as described by Taylor et al. (2002) and also by McDonald and Amstrup (2001) in which the number captured in year $i\left(n_{i}\right)$ is divided by the estimated recapture probability in year $i$ $\left(\hat{p}_{i}\right)$ :

$$
\hat{N}_{i}=\frac{n_{i}}{\hat{p}_{i}}
$$

We used the variance estimator in Taylor et al. (2002), which follows the approach of Huggins (1989) and Borchers et al. (1998):

$$
\operatorname{vâr}\left(\hat{N}_{i}\right)=\frac{n_{i}\left(1-\hat{p}_{i}\right)}{\hat{p}_{i}^{2}}+\frac{\hat{N}_{i}^{2}}{\hat{p}_{i}^{2}} \operatorname{vâr}\left(\hat{p}_{i}\right)
$$

When we stratified the population by age and sex, the total estimated population was the sum of stratum estimates and the variance estimator was extended to include covariances:

$\hat{N}_{i}=\sum_{j} \frac{n_{i j}}{\hat{p}_{i j}}$ and $\operatorname{vâr}\left(\hat{N}_{i}\right)=\sum_{j} \frac{n_{i j}\left(1-\hat{p}_{i j}\right)}{\hat{p}_{i j}^{2}}+\sum_{j} \sum_{j} \frac{n_{i j} n_{i j^{\prime}}}{\hat{p}_{i j}^{2} \hat{p}_{i j^{\prime}}^{2}} \operatorname{covv}\left(\hat{p}_{i j}, \hat{p}_{i j^{\prime}}\right)$

We used a similar estimator to construct a variance estimate for the average population size over several years.

Given our large sample of captured live bears, we did not need to include harvest returns explicitly in our markrecapture model; hence, our estimates of total survival $(S)$ derived from capture-recapture data and included losses from harvest. We were interested in estimating natural survival, $S_{N}$, to investigate potential impacts of alternative harvest strategies (see Harvest Risk Analysis, below). Because the total harvest of Lancaster Sound and Norwegian Bay polar bears was known, we used the approach outlined by Taylor et al. (2002) to estimate $S_{N}$ :

$$
\hat{S}_{N}=\frac{\hat{S}}{1-\frac{H}{\hat{N}}} \text { and } \operatorname{vâr}\left(\hat{S}_{N}\right)=\hat{S}_{N}^{2}\left[\frac{\operatorname{vâr}(\hat{S})}{\hat{S}^{2}}+\frac{\operatorname{vâr}(\hat{N}) h^{2}}{\hat{N}^{2}(1-h)^{2}}-2 \frac{\operatorname{covv}(\hat{N}, \hat{S})}{(1-h) \hat{N} \hat{S}}\right]
$$

where $h=H / N$.

\section{Reproduction}

We estimated reproductive parameters from the standing age distribution based on captures and recaptures that occurred inside the study area from 1993 to 1997 (Fig. 1). Each individual or family group was recorded by age as a male, solitary female, female with a cub, female with two cubs, female with a yearling, female with two yearlings, female with a 2-year-old, or female with two 2-year-old cubs.
Our methods for estimating litter size, age-specific litter production rates (for females aged $4,5,6$, and 7+ years), and sex ratio at birth from the standing age distribution are described in Taylor et al. (1987a, b) and available as the software package "Vital Rates" (Taylor et al., 2000). Standard errors of summary reproductive parameters were determined from Monte Carlo simulations with 1200 iterations. Litter production rates applied only to females that would have been available for mating the previous year, i.e., to females that did not possess cubs or yearlings-including cases of whole litter loss-in the previous year.

\section{Population Rate of Increase}

We calculated the geometric mean annual, zero-harvest finite rate of increase $\left(\lambda_{N}\right)$ of the population and the harvested (i.e., total) finite rate of increase $\left(\lambda_{H}\right)$ at stable-age distribution according to Taylor et al. (1987b, 2003). We ran 1200 Monte Carlo simulations to estimate the geometric mean of $\lambda$ using the life table-based Visual Basic program RISKMAN (Taylor et al., 2003, 2005; see also Dobey et al., 2005; McLoughlin et al., 2005; Wear et al., 2005; Clark and Eastridge, 2006; Howe et al., 2007), and estimated the standard error (SE) of $\lambda$ numerically as the standard deviation (SD) of the generated values (Manly, 1997). One important feature of RISKMAN is that it is designed to accommodate the multi-annual (3-year) life cycle of polar bears. It is also individual-based, in that the model tracks the fate and reproductive performance of simulated animals over the number of years specified by the user. For details of the model, including our approach to incorporating variance in parameter estimates, see Taylor et al. (2003).

\section{Harvest Risk Analysis}

We used RISKMAN (Taylor et al., 2003) to model population viability, i.e., the risk of future declines in polar bear populations given population parameters and uncertainty in data. RISKMAN can incorporate stochasticity into its population model at several levels, including sampling error in initial population size, variance in vital rates due to sample size and annual environmental variation (survival, reproduction, sex ratio), and demographic stochasticity. RISKMAN uses Monte Carlo techniques to generate a distribution of results (Manly, 1997) and then uses this distribution to estimate population size at a future time, population growth rate, and the proportion of runs that will result in a population decline set at a predetermined level by the user. We adopted the latter to estimate persistence probability.

Sampling error was applied only at the start of simulations, but environmental stochasticity at each year of simulation. Our approach to variance was to pool sampling and environmental variances for survival and reproduction initially and then partition effects for simulations (to interpret the potential range of effects) 
TABLE 1. Initial captures of polar bears classified by age and sex. Parentheses indicate the number of bears recaptured at least once in the years 1993-97. (Bears initially captured in 1997, the final year of the study, were never recaptured.)

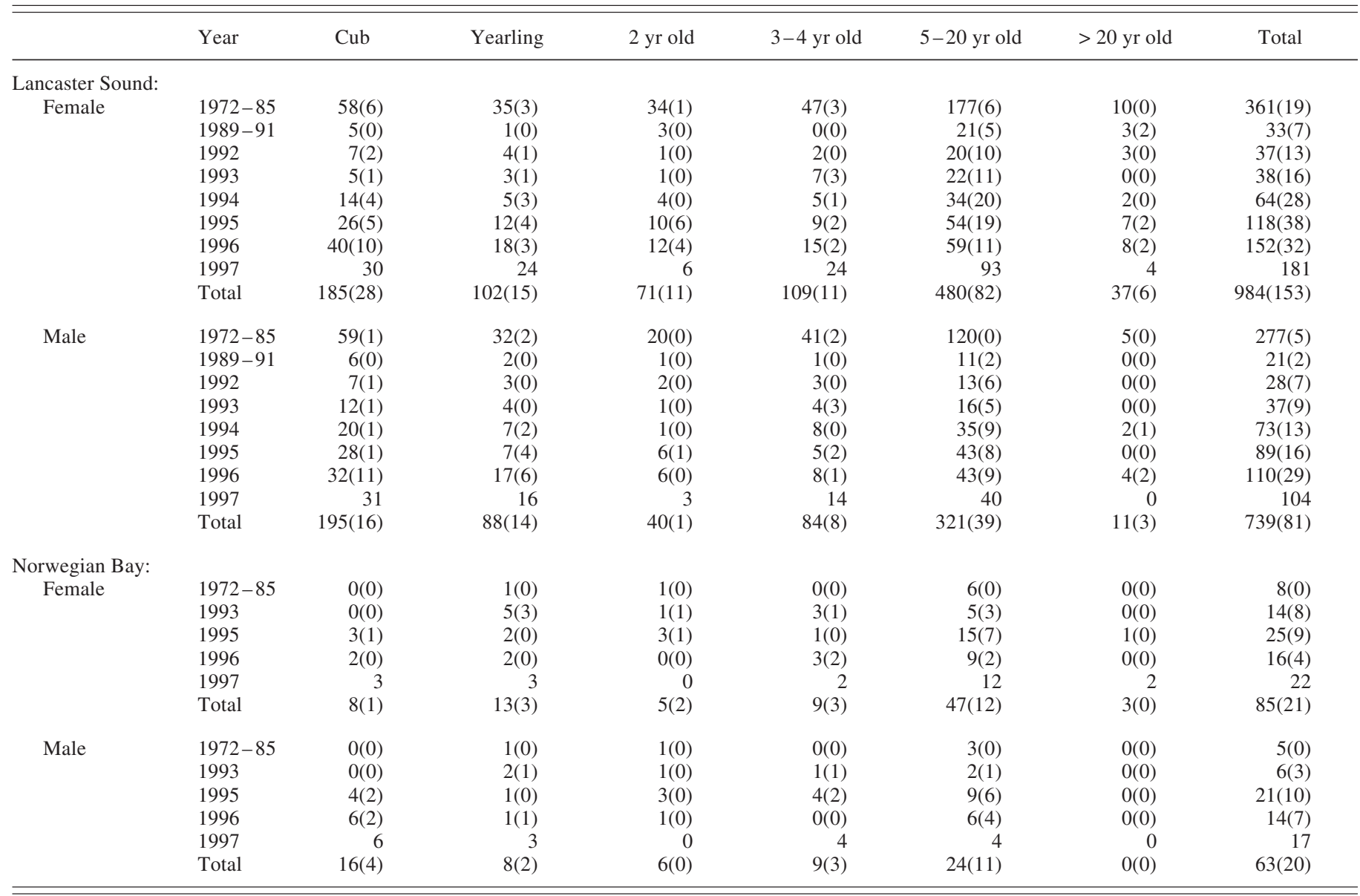

based on three ratios of sampling error to environmental error (3:1, 1:1, and 1:3). We did this because 1) our estimator of variances for reproductive parameters did not lend itself well to separating the sampling component of variance from environmental variance; 2 ) we were interested in quantifying the risks of population decline, including all sources of uncertainty in the data; and 3) we wished to illustrate the sensitivity of our results to differences in sampling vs. environmental sources of stochasticity.

For each simulation, the frequency of occurrence of unacceptable outcomes (based on a threshold value of decline from initial population size) was monitored and reported as the cumulative proportion of unacceptable runs after 15 years. We present a range of three thresholds of population decline: the likelihood of $10 \%$ decline after 15 years, $20 \%$ decline after 15 years, and any decline over the period of simulation. Thus 1 minus this last value represents the likelihood of population increase (i.e., a $50 \%$ likelihood of decline suggests the sustainable yield). We chose to conduct model projections over 15 years because 1) the population inventory cycle for this population is currently planned to be 15 years in duration, and 2) we do not advocate using PVA over long time periods in view of potential significant changes to habitat resulting from climate change in the Arctic (ACIA, 2004; Derocher et al., 2004; Aars et al., 2006). Individual runs could recover from "depletion," but not from a condition in which all males or all females or both were lost. Required population parameter estimates and standard error inputs included annual natural survival rate (stratified by age and sex as supported by the data); age of first reproduction; age-specific litter production rates for females available to have cubs, i.e., females with no cubs and females with twoyear-olds; litter size; the sex ratio of cubs; initial population size; and demographic distribution of the harvest.

The standing age distribution was female-biased, as expected from long-term, sex-biased harvesting (Table 1). Because we wished to err on the side of caution, we used the stable age distribution expected to be achieved by the population for a given harvest rate as the initial age/sex distribution for all simulations (i.e., initializing the population at the stable age distribution produced more conservative outcomes than using the existing standing age distribution). The harvest selectivity and vulnerability array was identified by comparing the standing age distribution of the historical kill to the projected stable age distribution under constant harvest. Harvest was stratified by sex, age (cubs and yearlings, ages $2-4$, ages $5-20$, and ages 21+) and family status (alone, or with cubs and yearlings, or with 2-year-olds). 
TABLE 2. $\triangle$ QAIC $_{c}$ values for the top 16 models fitted to Lancaster Sound and Norwegian Bay capture-recapture data, $1972-97$ (see text for definitions of abbreviations). The number of estimated parameters for each submodel is shown in parentheses. Values in bold type represent models used in model-averaging. Our estimate of the overdispersion coefficient, $\hat{c}$, was 1.23 . QAIC weights of the best four models, ranked from highest to lowest, were $0.590,0.264,0.092$, and 0.054 . Interaction terms included additive effects of interacting parameters (not shown).

\begin{tabular}{lcccc}
\hline \hline & \multicolumn{3}{c}{ Capture Model } \\
\cline { 2 - 5 } Survival Model & $\begin{array}{c}\text { pop } \times \text { year + radio } \\
(11)\end{array}$ & $\begin{array}{c}\text { pop } \times \text { year }+ \text { radio } \\
+ \text { dependence }(12)\end{array}$ & $\begin{array}{c}\text { pop } \times \text { year + radio } \\
+ \text { dependence }+ \text { age }(13)\end{array}$ & $\begin{array}{c}\text { pop } \times \text { year + radio } \\
+ \text { family + age/sex }(14)\end{array}$ \\
\hline age (4) & 22.6 & 7.0 & 8.5 & 20.2 \\
age $+\operatorname{sex}(5)$ & 13.9 & $\mathbf{0 . 0}$ & $\mathbf{1 . 6}$ & 8.7 \\
${ }^{1}$ age $\times \operatorname{sex}(7)$ & 17.5 & $\mathbf{3 . 7}$ & 5.0 & 12.2 \\
age $\times \operatorname{sex}(8)$ & 18.2 & $\mathbf{4 . 5}$ & 5.8 & 12.8 \\
\hline \hline
\end{tabular}

${ }^{1}$ Cub survival is the same for both sexes.

We ran harvest simulations using natural survival rates, to which we added incrementally increasing rates of kill (i.e., human-caused mortality from all sources). We elected to model harvest in an additive fashion because we wished to make no assumptions about compensatory harvesting, and thus our results may be conservative in this light. We present our harvest risk analysis as the estimated probability of decline from initial population size after 15 years vs. annual kill of bears. Simulations were time-referenced to the last year of study (1997).

\section{RESULTS}

\section{Captures, Recaptures, and Harvest}

We captured 984 females in Lancaster Sound and 85 females in Norwegian Bay from 1972 to 1997 (Table 1). Of these females, 153 and 21 bears, respectively, were recaptured at least once during 1993-97. We deployed radio collars on 44 females, 39 of 191 recaptures of females in Lancaster Sound and 5 of 25 in Norwegian Bay. Comparable figures for males during the same periods were 739 captures with 81 recaptures in Lancaster Sound and 63 captures with 20 recaptures in Norwegian Bay. The harvest between 1993 and 1997 averaged $71.6 \pm 5.7$ bears/yr (mean $\pm 1 \mathrm{SE}$ ) in Lancaster Sound and $3.2 \pm 1.3$ bears/yr in Norwegian Bay and was highly selective for male bears.

\section{Survival and Abundance}

A goodness-of-fit test using Test $2+$ Test 3 from RELEASE was performed with the data stratified by age groups to incorporate age effects into the strictly timedependent test and the result was a $\hat{c}$ less than unity. However, the data were insufficient for most cells of the test because of the age-stratification and the exclusion of recapture data from years before 1993 . We subsequently constructed a $\hat{c}=1.12$ using only the cells with adequate data. The ad-hoc approach that removes dependent cubs produced a $\hat{c}=1.23$; we used this estimate to account for over-dispersion in our models.
TABLE 3. Means and SE (in parentheses) of natural survival rates $\left(S_{N}\right)$ and total survival rates (harvest included, $S$ ) for polar bears of Lancaster Sound and Norwegian Bay, Nunavut, in 1993-97. Estimates are the weighted-averaged four best MARK models, pooled across populations as suggested by QAIC $_{c}$ model selection (Table 2).

\begin{tabular}{|c|c|c|c|}
\hline & & \multicolumn{2}{|c|}{ Mean Annual Survival Rate } \\
\hline \multicolumn{2}{|c|}{ Sex and Age } & $S_{N}$ & $S$ \\
\hline \multirow[t]{4}{*}{ Female } & 0 & $0.750(0.104)$ & $0.749(0.105)$ \\
\hline & $1-4$ & $0.898(0.050)$ & $0.879(0.050)$ \\
\hline & $5-20$ & $0.946(0.018)$ & $0.936(0.019)$ \\
\hline & $21+$ & $0.771(0.054)$ & $0.758(0.054)$ \\
\hline \multirow[t]{4}{*}{ Male } & 0 & $0.634(0.123)$ & $0.633(0.123)$ \\
\hline & $1-4$ & $0.838(0.075)$ & $0.790(0.073)$ \\
\hline & $5-20$ & $0.974(0.030)$ & $0.892(0.030)$ \\
\hline & $21+$ & $0.715(0.095)$ & $0.653(0.085)$ \\
\hline
\end{tabular}

Our best-fitting model specified sex and age effects in probabilities of survival and an effect of prior recapture (dependence) on capture probability (Table 2). Three additional models were sufficiently close to the best-fitting model to be included in a model average (Table 2): a model identical to the above with an added age effect for capture probability, and models identical to the first that included interaction effects for age and sex in survival probability (one model with cubs stratified by sex, and one without). The most parsimonious solution in our analysis of survival was to model survival rates as the same in both the Lancaster Sound and Norwegian Bay populations. In Table 2 we did not include the models with "population" in survival because they had a likelihood value nearly identical to that of the model without "population" and the effect size was essentially zero (e.g., -0.03 on the logit scale). Model-averaged, annual mean total survival rates $(S)$ and mean natural survival rates $\left(S_{N}\right)$ for the period 1993 to 1997 are presented in Table 3.

Annual estimates of total abundance (1995-97) averaged 2541 bears \pm 391 (mean \pm 1 SE) in Lancaster Sound, of which $1538 \pm 242$ bears were female and $1001 \pm 158$ bears were male. Of these, $502 \pm 87$ bears were cubs and $822 \pm 134$ bears were adult females (5+ years), suggesting 
TABLE 4. Estimates of the mean and SE (in parentheses) of summary reproductive parameters of polar bears inhabiting Lancaster Sound and Norwegian Bay in 1993-97. Parameters include cub litter size (LS), litter production rates (LPR) for females of age 4, 5, 6, and 7+, and the proportion of cub litters composed of males ([P] male). Note that litter production rates apply only to those females that would have been available for mating the previous year, i.e., females that did not possess cubs or yearlings (including cases of whole litter loss) in the previous year.

\begin{tabular}{|c|c|c|c|c|c|c|}
\hline & LS & LPR4 & LPR5 & LPR6 & LPR7+ & {$[\mathrm{P}]$ male } \\
\hline Lancaster Sound & $\begin{array}{l}1.69 \\
(0.03)\end{array}$ & $\begin{array}{l}0.000 \\
(0)\end{array}$ & $\begin{array}{c}0.107 \\
(0.050)\end{array}$ & $\begin{array}{c}0.312 \\
(0.210)\end{array}$ & $\begin{array}{c}0.954 \\
(0.083)\end{array}$ & $\begin{array}{c}0.531 \\
(0.048)\end{array}$ \\
\hline Norwegian Bay & $\begin{array}{c}1.71 \\
(0.08)\end{array}$ & $\begin{array}{c}0.000 \\
(0)\end{array}$ & $\begin{array}{l}0.000 \\
(0)\end{array}$ & $\begin{array}{l}0.000 \\
(0)\end{array}$ & $\begin{array}{c}0.689 \\
(0.534)\end{array}$ & $\begin{array}{c}0.544 \\
(0.066)\end{array}$ \\
\hline
\end{tabular}

an average natality (cubs per adult female) of 0.61 (range of $0.43-0.86$ considering SE of abundance estimates). The Norwegian Bay population was much smaller, averaging $203 \pm 44$ bears from 1995 to 1997. The Norwegian Bay population was composed on average of $107 \pm 25$ females and $92 \pm 23$ males, including $35 \pm 11$ cubs and $66 \pm 16$ adult females. We estimated natality for Norwegian Bay polar bears at 0.53 cubs per adult female.

\section{Reproduction}

Summary reproductive parameters for the Lancaster Sound and Norwegian Bay populations based on analysis of the standing age distribution of captures from 1993 to 1997 are presented in Table 4.

\section{Population Rate of Increase}

We calculated the stable-age, zero-harvest finite rate of increase for the Lancaster Sound population, $\lambda_{N}$, as 1.023 \pm 0.012 (mean $\pm 1 \mathrm{SE}$ ). The harvested rate of increase, $\lambda_{H}$, was $1.001 \pm 0.013$. The stable-age, zero-harvest finite rate of increase for the Norwegian Bay population was 1.006 \pm 0.016 , and the harvested rate of increase during the period of study was $0.981 \pm 0.027$.

\section{Harvest Risk Analysis}

The level of harvest in Lancaster Sound at which half the simulations showed population increase and half the simulations showed population decrease was very close to the historical harvest rate of 71.6 bears/yr (Fig. 2). For the period 1997-2012 (i.e., the 15 years following the end of study), the population would thus be expected to be stable under the historical harvest regimen (1993-97). At the current mean harvest rate of 78 bears/yr (5-yr mean, 2002 06), we estimate that the population is more likely to decline than to increase (Fig. 2). The Norwegian Bay population of polar bears likely declined during the period of study (see above). The current five-year mean kill of

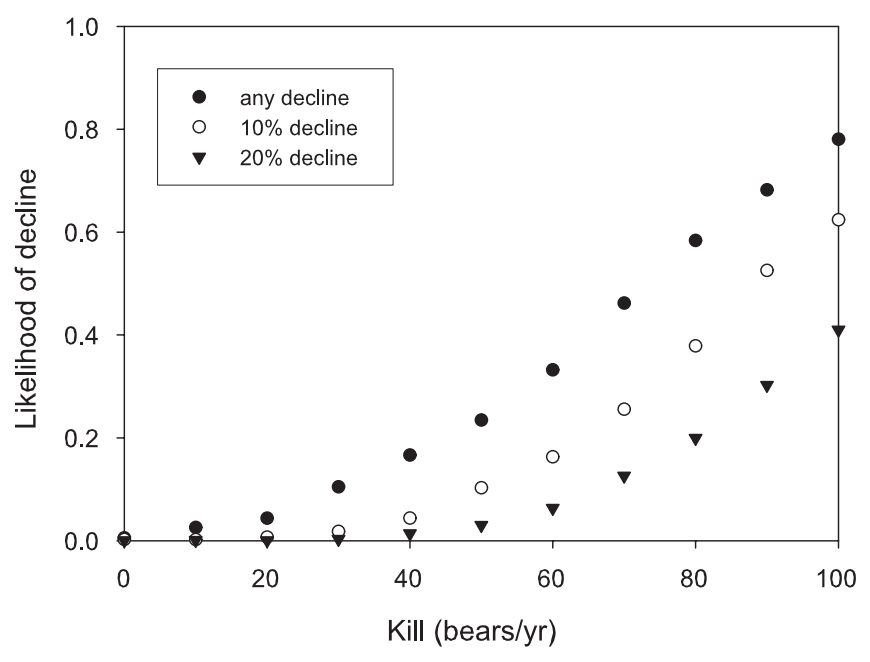

FIG. 2. Estimated probabilities of any decline (where 1 minus this value is the probability of population increase), $10 \%$ decline, and $20 \%$ decline from initial population size vs. annual kill for polar bears inhabiting Lancaster Sound for the period 1997-2012. Simulations assume that a 3:1 ratio of sampling vs. environmental variance is incorporated into the $\mathrm{SE}$ of parameters of survival and reproduction.

2.4 bears/yr (2002-06) in Norwegian Bay, although representing a reduction from levels during the period of study ( 3.2 bears/yr) and proportionately less than half the current rate in Lancaster Sound (1.2\% of $N$ vs. $3.1 \%$ of $N$ ), is also likely close to or in excess of the sustainable yield (Fig. 3). Partitioning sampling vs. environmental variances by ratios of $3: 1,1: 1$, and 1:3, respectively, had only a small effect on model outcomes, especially at higher levels of harvest (Fig. 4).

\section{DISCUSSION}

Although a single, constant survival rate for both the Lancaster Sound and Norwegian Bay populations gave the most parsimonious solution in our analysis, the unharvested, finite rates of increase of the two populations continued to differ substantially. We attributed lower population growth rate in Norwegian Bay to delayed age of reproduction and reduced productivity of Norwegian Bay females relative to females of Lancaster Sound. Females in Lancaster Sound reproduced as early as age five, while those in Norwegian Bay did not reproduce until at least age seven, and then only with a litter production rate that had greater uncertainty and was 25\% less than that of females in Lancaster Sound (Table 4). We must temper our conclusions because of the low sample size available from the much smaller Norwegian Bay population (Table 1); nonetheless, later age at first reproduction relative to more southerly Canadian polar bear populations was also observed for polar bears inhabiting Kane Basin, directly to the east and north of Norwegian Bay (M.K. Taylor, unpubl. data), on the opposite side of Ellesmere Island (Fig. 1). The Norwegian Bay and Kane Basin populations of polar bears represent the northernmost range of polar bears in North America. 


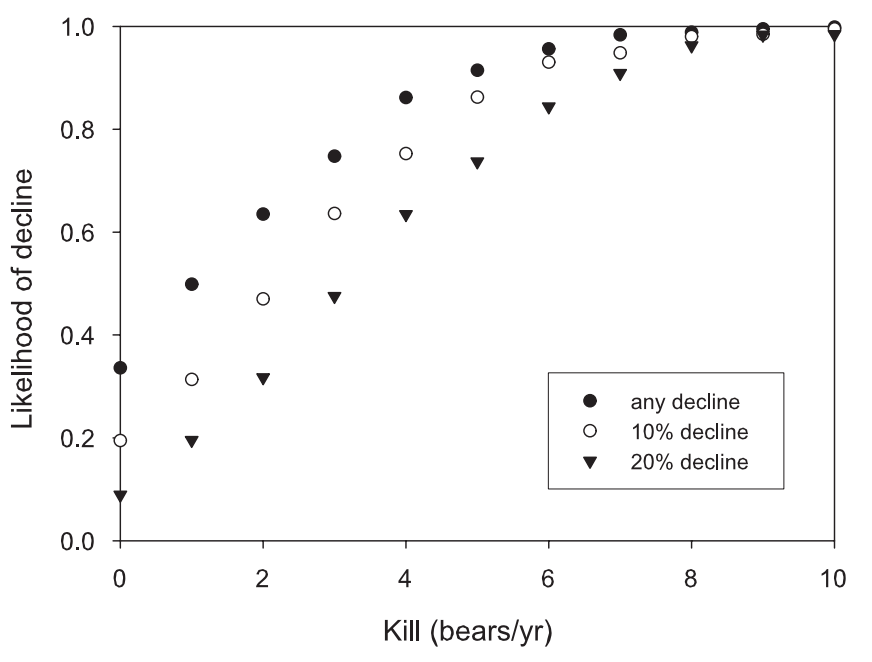

FIG. 3. Estimated probabilities of any decline (where 1 minus this value is the probability of population increase), $10 \%$ decline, and 20\% decline from initial population size vs. annual kill for polar bears inhabiting Norwegian Bay for the period 1997-2012. Simulations assume that a 3:1 ratio of sampling vs. environmental variance is incorporated into the SE of parameters of survival and reproduction.

In extreme environments, like the High Arctic, female bears are expected to allocate resources for reproduction in a safer, though less productive, manner (Ferguson and McLoughlin, 2000). Changes in life history that affect timing of reproduction (e.g., later age at maturity, longer inter-birth intervals, greater longevity; Cohen, 1970; Philippi and Seger, 1989; Sajah and Perrin, 1990) reduce the effects of extreme or stochastic environments, so that the geometric mean fitness of individuals is increased (Yoshimura and Jansen, 1996). For example, increased age at first reproduction has been observed for grizzly bear populations in response to reduced productivity and increased seasonality of the environment (Ferguson and McLoughlin, 2000). Polar bears in Norwegian Bay exhibit life history traits that appear adapted to extremes of the species' fundamental niche, including later reproduction than in other polar bear populations. We did not, however, detect any difference between the survival rates, longevity, or litter size of Norwegian Bay polar bears and other polar bear populations.

For large mammals, the outcome of life history adaptations to extreme environments is relatively low natural (unharvested) rates of population increase when populations are below carrying capacity. An example is the unharvested finite rate of increase observed for polar bears inhabiting Norwegian Bay $\left(\lambda_{N}=1.006\right)$, which is similar to that of polar bears of Kane Basin to the northeast $\left(\lambda_{N}=1.009 ;\right.$ M.K. Taylor, unpubl. data). Because of their long periods of historical harvest, we do not believe either population is currently at carrying capacity. These rates contrast significantly with unharvested population growth rates obtained for adjacent, but more southerly populations of polar bears, including the Lancaster Sound $\left(\lambda_{N}=1.023\right)$ population and the Baffin Bay population to the immediate southeast $\left(\lambda_{N}=1.055\right.$; Taylor et al., 2005). Intraspecific
A.

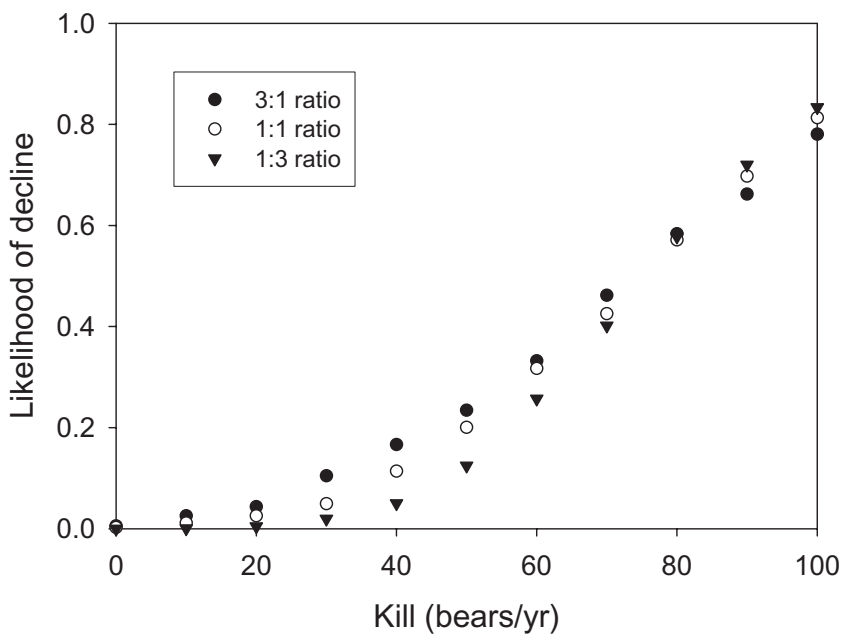

B.

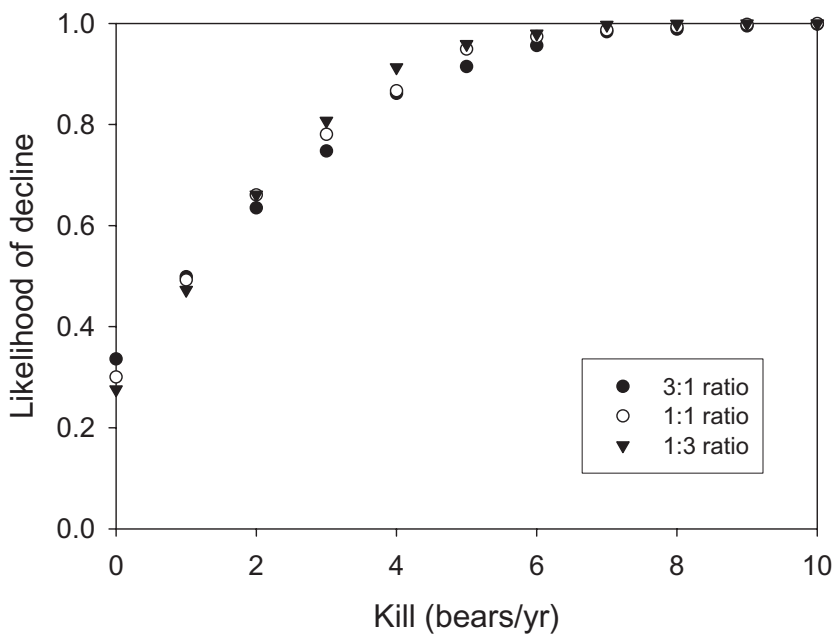

FIG. 4. Effects of partitioning variance in parameters of survival and reproduction based on $3: 1,1: 1$, and 1:3 ratios of sampling vs. environmental variance. A. Outcomes of simulations for the Lancaster Sound population (likelihood of any decline over 15 years). B. Outcomes of simulations for the Norwegian Bay population (likelihood of any decline over 15 years).

variation in life history entails the conclusion that not all populations of a species can, or should, be harvested at the same rate. Populations with relatively low intrinsic (Malthusian) rates of increase may not be safely harvested at levels that appear sustainable for other populations. We caution against taking harvest rates that were originally developed from data on polar bears from outside the Norwegian Bay boundary and applying them to polar bears within Norwegian Bay.

Although the difference between the annual harvest rate and unharvested growth rate of a population plays a primary role in determining the sustainability of a given harvest, it is not the only consideration when we estimate likelihoods of population persistence. If populations are small, population size requires special consideration when developing hunting quotas that allow for acceptable probabilities of population persistence. Discrete demographic units that are small are more susceptible to population decline because of the phenomenon of demographic stochasticity: that is, the importance of random chance in 
survival and reproduction for determining population trends increases as population size decreases (Caughley, 1977). The importance of demographic stochasticity at small population sizes was clearly evident in the outcomes of our simulated Norwegian Bay population of polar bears compared to those of Lancaster Sound (compare shapes of curves in Figs. 2 and 3). In nature, deterministic Allee effects (Allee, 1931) may also contribute to "extinction thresholds" for small populations, whereby individuals of populations that have been significantly reduced have difficulty finding mates, or are unable to engage in normal social interactions, resulting in per capita growth rates that approach or fall below zero at lower densities. The Norwegian Bay population is relatively small $(N=203)$, with an estimate of only 66 adult females, and estimating sustainable harvests in Norwegian Bay is complicated by the importance of demographic stochasticity in simulation results. Previous authors have cautioned against hunting discrete demographic units of bears approaching 100 individuals because of the unknown and potentially severe Allee effects or effects of demographic stochasticity (e.g., Wielgus, 2002).

Although we predict the Norwegian Bay population of polar bears to be more susceptible to overharvesting than that of Lancaster Sound, it is possible that, through emigration from the nearby and much larger Lancaster Sound population, polar bears might be harvested in Norwegian Bay at levels exceeding the sustainable yield without any observable decrease in population size. Potential "rescuing" of the population would depend on the degree to which individuals within Norwegian Bay constitute a discrete demographic unit. Unfortunately, both cluster analysis of movement data and genetic information suggest very low interchange between the two populations (Paetkau et al., 1999; Taylor et al., 2001). Relying on population interchange between Lancaster Sound and Norwegian Bay to improve prospects of models of persistence for Norwegian Bay bears is therefore not justified.

Our results suggest that the hunting of bears in Norwegian Bay should proceed only with extreme caution, and that even relatively small harvests can be detrimental to this population. Our simulations further suggest that recent harvests of 78 bears/yr in Lancaster Sound are exceeding the sustainable level of kill. Note, however, that extending simulation time horizons from 15 to 30 years results in a prediction of sustainability of the Lancaster Sound hunt at current levels. This discrepancy in results is likely due to an interaction between effects of uncertainty in initial population size and length of simulation on persistence probability-by running simulations over 30 years rather than 15 years we observe a reduced effect of variance in initial population size (which is applied only once at the start of each simulation) on the final population size. Nonetheless, extreme caution should be exerted when considering annual hunts of the Lancaster Sound polar bear population that exceed 70 bears/yr (i.e., the population's historical rate of harvest from 1972 to 1997), since we know that such levels must be approaching the sustainable yield.

Our risk assessment is an expression of the uncertainty in the demographic process and parameters. We suggest that our results are more realistic than a deterministic sustained yield estimate that does not consider the uncertainty of the underlying information. Both managers and stakeholders must recognize that scientific information rarely provides exact and absolutely correct harvest rate or harvest quota values. Researchers have a responsibility to quantify the uncertainty of their measurements and the uncertainty of their management recommendations. Reporting uncertainty in scientific results may help us to identify areas where local and traditional knowledge could be useful in guiding final management decisions. Such a framework for management is currently being used to manage polar bears throughout Nunavut.

\section{ACKNOWLEDGEMENTS}

This work was funded by the Government of Nunavut, the Polar Continental Shelf Project, the University of Saskatchewan, and the U.S. National Marine Mammal Laboratory. We thank all the local hunters and trappers that contributed their knowledge of polar bears in the Lancaster Sound and Norwegian Bay areas. M. Kuc was the primary programmer for RISKMAN and contributed to the development of its algorithms.

\section{REFERENCES}

AARS, J., LUNN, N.J., and DEROCHER, A.E. 2006. Polar bears. Proceedings of the 14th Working Meeting of the IUCN/SSC Polar Bear Specialist Group, Seattle, Washington, 20-24 June 2005. Occasional Paper of the IUCN Species Survival Commission No. 32. Gland, Switzerland: International Union for Conservation of Nature and Natural Resources. 189 p.

ACIA (ARCTIC CLIMATE IMPACT ASSESSMENT). 2004. Impacts of a warming climate: Arctic climate impact assessment. Cambridge: Cambridge University Press.

ALLEE, W.C. 1931. Animal aggregations: A study in general sociology. Chicago: Chicago University Press.

BETHKE, R., TAYLOR, M., AMSTRUP, S., and MESSIER, F. 1996. Population delineation of polar bears using satellite collar data. Ecological Applications 6:311-317.

BORCHERS, D.L., ZUCCHINI, W., and FEWSTER, R.M. 1998. Mark-recapture models for line transect surveys. Biometrics 54:1207-1220.

BURNHAM, K.P., and ANDERSON, D.R. 2002. Model selection and inference: A practical information-theoretic approach. New York: Springer-Verlag.

CALVERT, W., and RAMSAY, M.A. 1998. Evaluation of age determination of polar bears by counts of cementum growth layer groups. Ursus 10:449-453.

CAUGHLEY, G. 1977. Analysis of vertebrate populations. New York: John Wiley \& Sons. 
CLARK, J.D., and EASTRIDGE, R. 2006. Growth and sustainability of black bears at White River National Wildlife Refuge, Arkansas. Journal of Wildlife Management 70:1094-1101.

COHEN, D. 1970. The optimal timing of reproduction. American Naturalist 110:801-807.

DEROCHER, A.E., LUNN, N.J., and STIRLING, I. 2004. Polar bears in a warming climate. Integrative and Comparative Biology 44:163- 176.

DOBEY, S., MASTERS, D.B., SCHEICK, B.K., CLARK, J.D., PELTON, M.R., and SUNQUIST, M.E. 2005. Ecology of Florida black bears in the Okefenokee-Osceola ecosystem. Wildlife Monographs 158. $41 \mathrm{p}$.

FERGUSON, S.H., and McLOUGHLIN, P.D. 2000. Effect of energy availability, seasonality, and geographic range on brown bear life history. Ecography 23:193-200.

FREEMAN, M.M.R., and WENZEL, G. 2006. The nature and significance of polar bear conservation hunting in the Canadian Arctic. Arctic 59(1):21-30.

FURNELL, D.J., and SCHWEINSBURG, R.E. 1984. Population dynamics of Central Arctic polar bears. Journal of Wildlife Management 48:722-728.

HOWE, E.J., OBBARD, M.E., and SCHAEFER, J.A. 2007. Extirpation risk of an isolated carnivore population under different management scenarios. Journal of Wildlife Management 71: $603-612$.

HUGGINS, R.M. 1989. On the statistical analysis of capture experiments. Biometrika 76:33-40.

LEBRETON, J.D., BURNHAM, K.P., CLOBERT, J., and ANDERSON, D.R. 1992. Modelling survival and testing biological hypotheses using marked animals: A unified approach with case studies. Ecological Monographs 62:67-118.

MANLY, B.F.J. 1997. Randomization, bootstrap and Monte Carlo methods in biology. London: Chapman \& Hall.

McDONALD, T.L., and AMSTRUP, S.C. 2001. Estimation of population size using open mark-recapture models. Journal of Agricultural, Biological, and Environmental Statistics 6: 206-220.

McLOUGHLIN, P.D., TAYLOR, M.K., and MESSIER, F. 2005. Conservation risks of male-selective harvest for mammals with low reproductive potential. Journal of Wildlife Management 69:1592-1600.

PAETKAU, D., AMSTRUP, S.C., BORN, E.W., CALVERT, W., DEROCHER, A.E., GARNER, G.W., MESSIER, F., STIRLING, I., TAYLOR, M.K., WIIG, Ø., and STROBECK, C. 1999. Genetic structure of the world's polar bear populations. Molecular Ecology 8:1571-1584.

PHILIPPI, T., and SEGER, J. 1989. Hedging one's evolutionary bets, revisited. Trends in Ecology and Evolution 4:41-44.

SAJAH, H., and PERRIN, N. 1990. Autumnal vs. spring hatching in the fairy shrimp Siphonophanes grubii (Dybowski)(Crustacea, Anostraca): Diversified bet-hedging strategy? Functional Ecology 4:769-775.

SCHWEINSBURG, R.E., FURNELL, D.J., and MILLER, S.J. 1981. Abundance, distribution, and population structure of polar bears in the lower Central Arctic Islands. Wildlife Service Completion Report Number 2. Yellowknife: Government of the Northwest Territories.
SCHWEINSBURG, R.E., LEE, L.J., and LATOUR, P.B. 1982. Distribution, movements and abundance of polar bears in Lancaster Sound, Northwest Territories. Arctic 35(1):159-169.

STIRLING, I., SPENCER, C., and ANDRIASHEK, D. 1989. Immobilization of polar bears (Ursus maritimus) with Telazol in the Canadian Arctic. Journal of Wildlife Disease 25:159-168.

TAYLOR, M.K., and LEE, L.J. 1995. Distribution and abundance of Canadian polar bear populations: A management perspective. Arctic 48:147-154.

TAYLOR, M.K., BUNNELL, F., DeMASTER, D., SCHWEINSBURG, R., and SMITH, J. 1987a. ANURSUS: A population analysis system for polar bears (Ursus maritimus). International Conference on Bear Research and Management 7:117-125.

TAYLOR, M.K., CARLEY, J.S., and BUNNELL, F.L. 1987b. Correct and incorrect use of recruitment rates for marine mammals. Marine Mammal Science 3:171-178.

TAYLOR, M.K., KUC, M., and ABRAHAM, D. 2000. Vital rates: Population parameter analysis program for species with threeyear reproductive schedules. Iqaluit: Government of Nunavut.

TAYLOR, M.K., AKEEAGOK, S., ANDRIASHEK, D., BARBOUR, W., BORN, E.W., CALVERT, W., FERGUSON, S., LAAKE, J., ROSING-ASVID, A., STIRLING, I., and MESSIER, F. 2001. Delineating Canadian and Greenland polar bear (Ursus maritimus) populations by cluster analysis of movements. Canadian Journal of Zoology 79:690-709.

TAYLOR, M.K., LAAKE, J., CLUFF, H.D., RAMSAY, M., and MESSIER, F. 2002. Managing the risk from hunting for the Viscount-Melville Sound polar bear population. Ursus 13: 185-202.

TAYLOR, M.K., OBBARD, M., POND, B., KUK, M., and ABRAHAM, D. 2003. A guide to using RISKMAN: Stochastic and deterministic population modeling RISK MANagement decision tool for harvested and unharvested populations. Version 1.9. Peterborough: Ontario Ministry of Natural Resources. Also available from http://www.nrdpfc.ca/riskman/riskman.htm.

TAYLOR, M.K., LAAKE, J., McLOUGHLIN, P.D., BORN, E.W., CLUFF, H.D., FERGUSON, S.H., ROSING-ASVID, A., SCHWEINSBURG, R., and MESSIER, F. 2005. Demography and viability of a hunted population of polar bears. Arctic 58(2): $203-214$.

WEAR, B.J., EASTRIDGE, R., and CLARK, J.D. 2005. Factors affecting settling, survival, and viability of black bears reintroduced to Felsenthal National Wildlife Refuge, Arkansas. Wildlife Society Bulletin 33:1363-1374.

WHITE, G.C. 2000. Population viability analysis: Data requirements and essential analyses. In: Boitani, L., and Fullers, T.K., eds. Research techniques in animal ecology: Controversies and consequences. New York: Cambridge University Press. 288-331.

WHITE, G.C., and BURNHAM, K.P. 1999. Program MARK: Survival estimation from populations of marked animals. Bird Study Supplement 46:120-138.

WIELGUS, R.B. 2002. Minimum viable population and reserve sizes for naturally regulated grizzly bears in British Columbia. Biological Conservation 106:381-388.

YOSHIMURA, J., and JANSEN, V.A.A. 1996. Evolution and population dynamics in stochastic environments. Researches on Population Ecology 38:165-182. 